\title{
Simplified Modeling of a DFIG for Transient Studies in Wind Power Applications
}

\author{
Alvaro Luna, Student Member, IEEE, Francisco Kleber de Araujo Lima, David Santos, \\ Pedro Rodríguez, Senior Member, IEEE, Edson H. Watanabe, Senior Member, IEEE, and \\ Santiago Arnaltes, Member, IEEE
}

\begin{abstract}
Improving the fault ride-through (FRT) capability of doubly fed induction generators (DFIGs) in wind power applications is a very important challenge for the wind power industry. The mathematical models of such generators enable us to analyze their response under generic conditions. However, their mathematical complexity does not contribute to simplifying the analysis of the system under transient conditions and hence does not help in finding straightforward solutions for enhancing their FRT. This paper presents a simplified model of the DFIG, which has been extracted from the classical fifth-order model, which can accurately estimate the behavior of the system while significantly reducing its complexity. In this paper, the mathematical deduction of this model will be presented, and simulations and experimental results will be shown to demonstrate the accuracy and reliability of the proposed algorithm.
\end{abstract}

Index Terms-AC generators, current control, electric variables control, wind power generation.

\section{INTRODUCTION}

W IND POWER generation has significantly increased during the last years. The European wind power industry has formulated generation targets of $180 \mathrm{GW}$ in 2020 and $300 \mathrm{GW}$ by the end of 2030 [1]-[4]. Experiences in countries with high penetration of wind power, such as Denmark, Spain, and Germany, together with national power system studies [5], have demonstrated that this scenario is technically and economically feasible.

However, the rapid expansion of this energy has made it necessary to redesign the existing grid code requirements (GCR).

The transmission system operators (TSOs) currently demand more reliability to wind power technologies; therefore, stan-

Manuscript received August 3, 2009; revised November 20, 2009; accepted January 25, 2010. Date of publication April 12, 2010; date of current version December 10, 2010. This work was supported by the Spanish Ministry of Science and Innovation under Project ENE2008-06588-C04-03/ALT.

A. Luna is with the Department of Electrical Engineering, Technical University of Catalonia (UPC), Barcelona 08222, Spain (e-mail: luna@ee.upc.edu).

F. K. de Araujo Lima is with the Energy Processing and Control Group, Department of Electrical Engineering, Federal University of Rio de Janeiro, 21945-970 Rio de Janeiro, Brazil (e-mail: kleber@coe.ufrj.br).

D. Santos and S. Arnaltes are with the Department of Electrical Engineering, University Carlos III of Madrid, Madrid 28911, Spain (e-mail: dsmartin@ ing.uc3m.es; arnalte@ing.uc3m.es).

P. Rodríguez is with the Research Group on Renewable Electrical Energy Systems, Department of Electrical Engineering, Technical University of Catalonia (UPC), Barcelona 08222, Spain (e-mail: prodriguez@ee.upc.edu).

E. H. Watanabe is with the Alberto Luiz Coimbra Institute and Graduate School of Research and Engineering (COPPE), Federal University of Rio de Janeiro, 21945-970 Rio de Janeiro, Brazil (e-mail: watanabe@ @oe.ufrj.br).

Color versions of one or more of the figures in this paper are available online at http://ieeexplore.ieee.org.

Digital Object Identifier 10.1109/TIE.2010.2044131

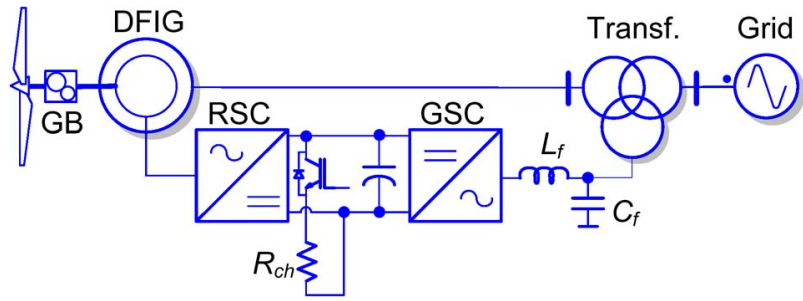

Fig. 1. Grid-connected DFIG WT with a back-to-back converter.

dards with regard to the connection, operation, and maintenance of such power plants become more restrictive [6]-[10].

In this scenario, simulation tools such as PSCAD or PSS, where the distributed generation networks can be analyzed in deep, have gained a great importance for designing advanced functionalities and control strategies to improve the integration of wind energy.

Currently, wind power systems that are based on doubly fed induction generators (DFIGs), which are controlled by back-toback power converters, constitute almost $50 \%$ of the installed wind turbines (WTs) worldwide in on-shore applications [11]. The layout of a WT that is based on this technology is shown in Fig. 1.

As explained in [12], the success of this kind of WTs lies in the fact that it offers a good solution for controlling the active and reactive power generation, in a reasonable $\pm 30 \%$ range around the generator's nominal power [13], [14].

Although the operation of DFIG WTs is satisfactory under grid balanced conditions, its performance is not so good when the voltage at the point of common coupling (PCC) is affected by voltage sags or network unbalances [15], [16]. Under such conditions, the electromagnetic transient of the DFIG gives rise to high overcurrents in the converter, which may produce its disconnection to avoid damages in the semiconductors.

Different authors have published solutions, which are oriented to enhance the fault ride-through (FRT) capability of DFIG WTs under these transient conditions [15]-[24]. Many of the solutions are based on implementing advanced functionalities on the existing rotor/grid-side converters. In all cases, it has been found that an accurate study about the performance of the generator is helpful to propose reliable solutions [25], [26].

The fifth-order model of DFIG-based WTs has extensively been used to study its behavior under generic conditions, as demonstrated in [27]-[30]. However, this kind of model gives rise to a complicated system that does not enable carrying out a simple analytical study of the DFIG under transient conditions. 
Moreover, the high computational cost of the equation in standards simulators such as Matlab, PSS, or PSCAD does not enable the simultaneous simulation of a whole wind farm, hence developing aggregated models is necessary [31].

To overcome these problems, a simplified third-order model was presented in [32], based on the works developed in [33] and [34]. This proposal simplifies the fifth-order model by neglecting the stator electric transients. However, the unbalanced effects in the network voltage are not taken into account, as demonstrated in [35]. Due to these features, this model is not valid for studying the FRT in DFIGs.

However, a simplified modeling can be carried out without neglecting the dynamics of the voltage, as stated in [36]. Considering this issue, this paper is devoted to present a new simplified model of the DFIG, different from the third-order approach, which permits having a more intuitive estimation of the generator's behavior under transient conditions. The proposed system simplifies the fifth-order model by considering the following criteria: 1) certain components of the equations, with low weight in the system, can be neglected; 2) the rotorside converter acts as a current source based on a field-oriented control (FOC) algorithm [27]-[29]; and 3) the selected synchronous reference frame enables simplifying some terms of the stator voltage. Taking these conditions into account, simple expressions for calculating the injected currents through the stator, in function of the rotor currents and the network voltage, can be found. As it will be discussed, the resulting model is useful for designing new control solutions, which are oriented to enhance the FRT of DFIG WTs.

In this paper, the classical modeling of DFIGs will shortly be presented in Section II. The simplified model equations will be deduced in Sections III and IV, and some simulation results, that will be shown in Section V, will demonstrate that the small differences obtained, if compared with a fifth-order model. In Section VI, the experimental case study for testing the performance of the simplified model will be presented. Finally, in Section VII, different experimental results will show the accuracy of the proposed algorithm.

\section{Fifth-ORder Model of DFIG}

The mathematical model of the DFIG, which will later be simplified in this paper, is presented here, considering the generator's variables in the $d q$ synchronous reference frame. The equations for the stator and rotor windings can be written as

$$
\begin{aligned}
& v_{d s}=r_{s} i_{d s}+\frac{d \lambda_{d s}}{d t}-\omega_{s} \lambda_{q s} \\
& v_{q s}=r_{s} i_{q s}+\frac{d \lambda_{q s}}{d t}+\omega_{s} \lambda_{d s} \\
& v_{d r}=r_{r} i_{d r}+\frac{d \lambda_{d r}}{d t}-\left(\omega_{s}-\omega_{r}\right) \lambda_{q r} \\
& v_{q r}=r_{r} i_{q r}+\frac{d \lambda_{q r}}{d t}+\left(\omega_{s}-\omega_{r}\right) \lambda_{d r} .
\end{aligned}
$$

The $d-q$ synchronous reference frame equations of the stator flux and rotor may be written also as

$$
\begin{array}{ll}
\lambda_{d s}=L_{s} i_{d s}+L_{m} i_{d r} & \lambda_{q s}=L_{s} i_{q s}+L_{m} i_{q r} \\
\lambda_{d r}=L_{r} i_{d r}+L_{m} i_{d s} & \lambda_{q r}=L_{r} i_{q r}+L_{m} i_{q s} .
\end{array}
$$

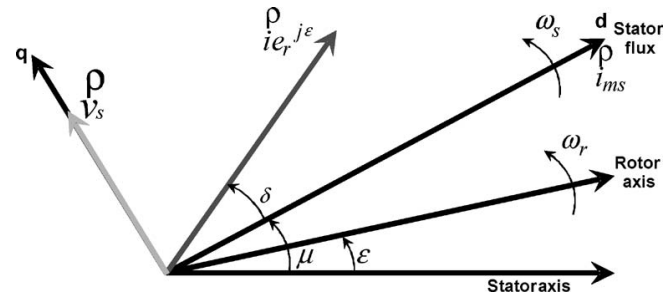

Fig. 2. Vectorial diagram in the $d q$ reference frame, considering a fieldoriented control philosophy.

By substituting (5) and (6) in (1)-(4), it is possible to obtain a state space model based on the current components.

Once the rotor and stator currents are found, the electromagnetic torque and the active/reactive power at the stator windings can be calculated as follows:

$$
\begin{aligned}
T_{e} & =\frac{3}{2} \frac{L_{m}}{L_{s}} p\left(\lambda_{q s} i_{d s}-\lambda_{d s} i_{q s}\right) \\
P_{s} & =v_{d s} i_{d s}+v_{q s} i_{q s} \\
Q_{s} & =v_{d s} i_{q s}-v_{q s} i_{d s} .
\end{aligned}
$$

Finally, the mechanical dynamics of the system, which is given by

$$
J \frac{d \omega_{r}}{d t}+B \omega_{r}=T_{\mathrm{mec}}-T_{e}
$$

together with (1)-(4), constitute the fifth-order model of the DFIG that will be considered in this paper.

\section{Classical FOC Control of DFIG}

In wind power systems, based on DFIG WTs, the most widely used method for controlling the injection of $P$ and $Q$ into the electrical network is based on the FOC principle. This algorithm enables performing a decoupled control of the positive sequence of $P$ and $Q$ by regulating the $d q$ components of the rotor currents that are injected to the DFIG [37], [38].

In this control strategy, the rotor-side converter acts as a current-controlled power converter, whose variables are referred to a rotating reference frame that is oriented alongside the stator magnetic flux vector position, as shown in Fig. 2. As a consequence of this approach and considering that the stator resistance is very low, the FOC performs the following assumptions.

1) The positive sequency of the stator voltage has a single component in the $q$-axis.

2) The positive sequency of the stator flux is totally aligned with the $d$-axis.

If both conditions are mixed with (8) and (9), the positive sequence active/reactive power that is injected through the stator can be written as

$$
P_{s}=v_{q s} i_{q s} \quad Q_{s}=-v_{q s} i_{d s} .
$$

The stator currents in the last equation can be written in function of the rotor currents as follows, as demonstrated in 
[27]-[29]:

$$
\begin{aligned}
& i_{q s}=-\frac{L_{M}}{L_{r r}} \cdot i_{q r} \\
& i_{d s}=i_{m}-\frac{L_{M}}{L_{r r}} \cdot i_{d r} .
\end{aligned}
$$

In this last expression, $i_{m}$ is considered to be the magnetizing current of the generator. Although this value is a bit lower than the real one, it is a reasonable approximation. Based on these expressions, together with (11), it can be concluded that the inquadrature current component of the rotor $i_{q r}$ can be used to regulate the active power that is delivered by the stator, whereas the direct current $i_{d r}$ is responsible for controlling the stator reactive power.

The FOC can be extended to also regulate the negative sequence active/reactive power delivery by extending the positive sequence control to the negative-sequence synchronous reference frame, as shown in [16] and [17]. However, the advanced control of the DFIG's rotor converter is out of the scope of this paper; therefore, a simple controller that considers the positive sequence components will be implemented.

\section{Simplified Modeling OF DFIG}

The objective of this section will be focused on finding a simple relationship between the state space variables and the outputs of a DFIG, which can enable us to easily predict its behavior under transient and fault conditions.

As shown in many publications, the fifth-order model is a useful tool for modeling the behavior of the generator as an electrical machine. However, considering that the DFIG in wind power applications belongs to an electrical system where other components such as the power converters, which are responsible for controlling their operation, and the electrical networks where it is connected are involved, several simplifications can be made.

Considering that the objective of a DFIG is to deliver a certain power to the network and, therefore, to control the injected currents and assuming that the rotor-side converter serves as a current source, the response of the DFIG depends on only three variables: 1) the voltage and frequency of the network; 2) rotor currents; and 3) the speed of the rotor.

\section{A. Simplified Model Analysis}

Considering that the system described by (1)-(6) is linear and after applying the Laplace transform, it is possible to obtain the stator currents in the synchronous reference frame shown in (14) and (15) as follows:

$$
\begin{aligned}
i_{d s}= & \frac{\overbrace{\left(L_{s} s+R_{s}\right) v_{d s}}^{v_{d s} \text { term }}+\overbrace{\omega_{s} L_{s} v_{q s}}^{v_{q s} \text { term }}}{\left(L_{s}^{2} s^{2}+2 L_{s} R_{s} s+R_{s}^{2}+\omega_{s}^{2} L_{s}^{2}\right)} \\
& -\frac{\left(L_{s} s^{2}+R_{s} s+\omega_{s}^{2} L_{s}\right) L_{m} i_{d r}-R_{s} \omega_{s} L_{m} i_{q r}}{\left(L_{s}^{2} s^{2}+2 L_{s} R_{s} s+R_{s}^{2}+\omega_{s}^{2} L_{s}^{2}\right)}
\end{aligned}
$$

$$
\begin{aligned}
i_{q s}= & \frac{\overbrace{-\omega_{s} L_{s} v_{d s}}^{v_{d s} \text { term }}+\overbrace{\left(L_{s} s+R_{s}\right) v_{q s}}^{v_{q s} \text { term }}}{\left(L_{s}^{2} s^{2}+2 L_{s} R_{s} s+R_{s}^{2}+\omega_{s}^{2} L_{s}^{2}\right)} \\
& -\frac{R_{s} \omega_{s} L_{m} i_{d r}+\left(L_{s} s^{2}+R_{s} s+\omega_{s}^{2} L_{s}\right) L_{m} i_{q r}}{\left(L_{s}^{2} s^{2}+2 L_{s} R_{s} s+R_{s}^{2}+\omega_{s}^{2} L_{s}^{2}\right)} \\
i_{d s}= & \frac{\omega_{s} L_{s} v_{q s}}{\left(L_{s} s^{2}+2 R_{s} s+\omega_{s}^{2} L_{s}\right) L_{s}} \\
& -\frac{\left(L_{s} s^{2}+R_{s} s+\omega_{s}^{2} L_{s}\right) L_{m} i_{d r}-R_{s} \omega_{s} L_{m} i_{q r}}{\left(L_{s} s^{2}+2 R_{s} s+\omega_{s}^{2} L_{s}\right) L_{s}} \\
i_{q s}= & \frac{\left(L_{s} s+R_{s}\right) v_{q s}}{\left(L_{s} s^{2}+2 R_{s} s+\omega_{s}^{2} L_{s}\right) L_{s}} \\
& -\frac{R_{s} \omega_{s} L_{m} i_{d r}+\left(L_{s} s^{2}+R_{s} s+\omega_{s}^{2} L_{s}\right) L_{m} i_{q r}}{\left(L_{s} s^{2}+2 R_{s} s+\omega_{s}^{2} L_{s}\right) L_{s}} .
\end{aligned}
$$

Considering that the modeling of the DFIG should be valid under grid voltage balanced and unbalanced conditions, the $v_{d s}$ cannot directly be neglected in any of the expressions. However, the weights of the terms that are multiplied by this component are very low compared with the $v_{q s}$ terms. This observation will later be demonstrated through simulation results.

If these terms are neglected, the expressions (14) and (15) can be rewritten as shown in (16) and (17).

In the second term of both expressions, the effect of the rotor currents that are affected by $R_{s} \omega_{s} L_{m}$ can be neglected due the low value of this term compared with the coefficient $\left(L_{s} s^{2}+\right.$ $\left.R_{s} s+\omega_{s}^{2} L_{s}\right) L_{m}$. Moreover, considering that the quotient in (18) is almost equal to 1 , the final simplified model can be obtained as detailed in (19) and (20), i.e.,

$$
\frac{\left(L_{s} s^{2}+R_{s} s+\omega_{s}^{2} L_{s}\right)}{\left(L_{s} s^{2}+2 R_{s} s+\omega_{s}^{2} L_{s}\right)} \cong 1
$$

In both equations, the rotor current and the stator voltage appear as the input variables, because the first one is fixed by the rotor side converter, whereas $v_{q s}$ depends on the grid behavior.

As it can be concluded based on (19) and (20), any variation in the stator voltage introduces oscillations in the $d q$ components of the stator currents in the synchronous reference frame. The frequency of such oscillation is equal to the grid frequency, and its damping is very poor due to the low value of the stator resistance $R_{s}$ (generally around $0.005 \mathrm{pu}$ ), i.e.,

$$
\begin{aligned}
& i_{d s}=\frac{1}{L_{s}} \frac{\omega_{s}}{s^{2}+2\left(R_{s} / L_{s}\right) s+\omega_{s}^{2}} v_{q s}-\frac{L_{m}}{L_{s}} i_{d r} \\
& i_{q s}=\frac{1}{L_{s}} \frac{s+R_{s} / L_{s}}{s^{2}+2\left(R_{s} / L_{s}\right) s+\omega_{s}^{2}} v_{q s}-\frac{L_{m}}{L_{s}} i_{q r} .
\end{aligned}
$$

This phenomenon can specially be noticed when voltage sags occur [39], [40]. If there is a balanced sag, the stator currents in $d q$ oscillate at $\omega_{s}$; in addition, if the sag is unbalanced, the negative sequence components that appear force oscillations with a frequency equal to $2 \omega_{s}$ in the voltage $e_{s}$, which shall be added to the $\omega_{s}$ ones, which are generated by the sudden change in the positive sequence magnitude. 
TABLE I

SPECification OF Simulated Systems

\begin{tabular}{ll}
\hline \multicolumn{1}{c}{ Machine parameters } & \multicolumn{1}{c}{ Values } \\
\hline Rated power & $100 \mathrm{kVA}$ \\
Rated stator voltage & $220 \mathrm{~V}$ \\
Rated rotor voltage & $220 \mathrm{~V}$ \\
Rated stator current & $340 \mathrm{~A}$ \\
Rated stator frequency & $60 \mathrm{~Hz}$ \\
Stator resistance & $2.6 \mathrm{~m} \Omega$ \\
Rotor resistance & $2.9 \mathrm{~m} \Omega$ \\
Stator leakage inductance & $138.66 \mu \mathrm{H}$ \\
Rotor leakage inductance & $141.22 \mu \mathrm{H}$ \\
Mutual inductance & $5.6 \mathrm{mH}$ \\
Angular moment of inertia $(\mathrm{J}=2 \mathrm{H})$ & $0.5 \mathrm{pu}$ \\
Poles pairs & 1 \\
\hline
\end{tabular}

As it will be shown in the following discussion, the performance of the DFIG stator currents can easily be predicted when using only the simplified model, detailed in (19) and (20). This issue is very useful, as the behavior of the generator under transient and unbalanced conditions is currently of great interest. Hence, a simplified model that can represent the system under such conditions can be useful for proposing possible solutions that are oriented to improve its FRT response.

\section{Simulation Results}

In this section, the simplified DFIG model, as presented in (19) and (20), has been validated through simulations that are carried out in PSCAD/EMTDC. The parameters of the simulated model are shown in Table I.

Due to the specific interest of this model for predicting the DFIG's performance under transient conditions, three different voltage sags have been analyzed. To validate the accuracy of the simplified model, with respect to the resolution of a fifthorder model, the responses of both systems have been plotted together in the same graph.

\section{A. Performance Under Three-Phase Fault}

The first test was conducted by considering a three-phase fault. The voltage waveforms that are associated with this voltage sag are plotted in Fig. 3(a). As shown in the figure, the sag occurs at $t=2 \mathrm{~s}$ and lasts after $200 \mathrm{~ms}$. The active and reactive power delivery through the stator is shown in Fig. 3(b). Based on the figure, the sudden voltage reduction gives rise to a lower power injection into the network. This behavior also depends on the control of the rotor-side converter during the fault. However, this issue is out of the scope of this paper, and hence, no further details will be analyzed.

The behavior of the $i_{d s}$ and $i_{q s}$ currents when using the fifthorder and the simplified models are plotted in Fig. 3(c) and (d). In both cases, it can clearly be noticed how the simplified model response perfectly matches the dynamical performance of the fifth-order model. To show the low influence of the $v_{d s}$ term in (19) and (20), which is neglected in the simplified model, its response is also shown in Fig. 3(c) and (d) as a third plot. In this experiment, it is worth pointing out that the oscillations that appear in $i_{d s}$ and $i_{q s}$ are due to the low damping of the system. (a)

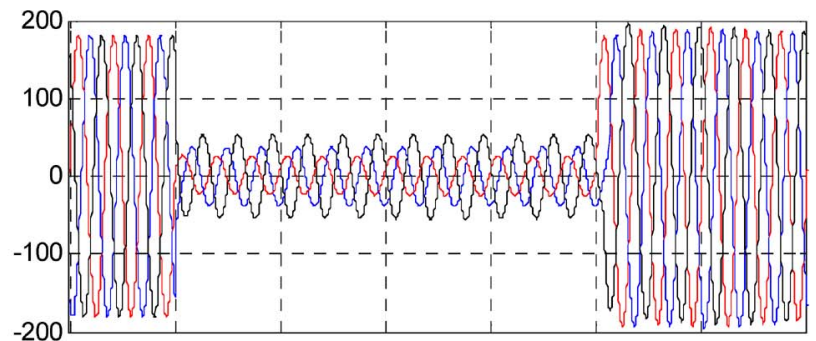

(b)

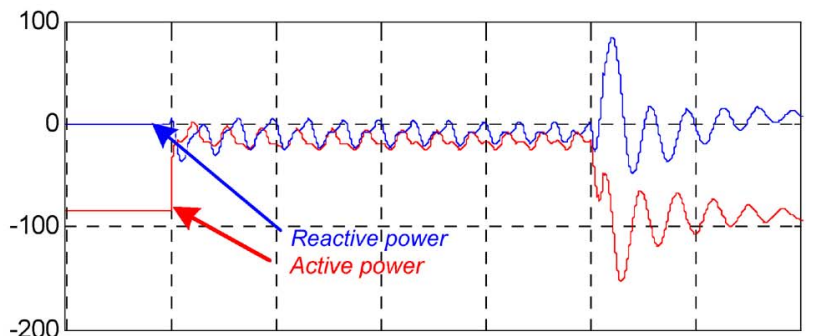

(c)

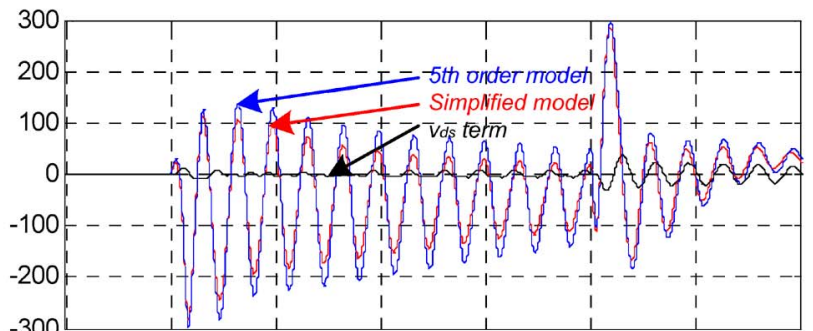

(d)

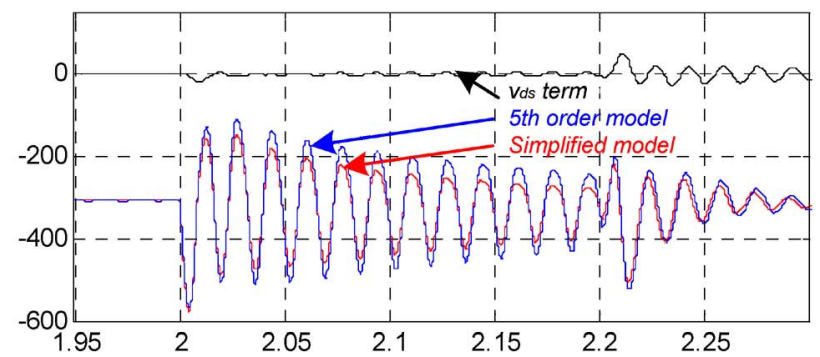

Fig. 3. Behavior of the DFIG models under three-phase-to-ground faults. (a) Grid voltage waveforms. (b) Active and reactive power (in kilovoltamperes). (c) $i_{s q}$ performance with the simplified and fifth-order models. (d) $i_{s d}$ performance with the simplified and fifth-order models.

As shown in (19) and (20), the relationship between the voltage with the output currents can be approximated by a secondorder transfer function, where the damping is conditioned by the value or $R_{s}$, which is quite low in DFIGs.

\section{B. Performance Under One-Phase-to-Ground Fault}

The second simulation test is focused on studying the influence of the system when a one-phase-to-ground fault affects the stator windings. As stated in [5], this kind of fault constitutes the $95 \%$ of the overall voltage sags that appear in the electrical network. Moreover, this test is of special interest due to the appearance of a negative sequence voltage at the stator.

In Fig. 4(a), the stator voltage waveforms are presented. In Fig. 4(b), the behavior of the active/reactive power delivery through the stator is shown. Finally, in Fig. 4(c) and (d), the response that was obtained with the simplified and full-order models for $i_{d s}$ and $i_{q s}$ is displayed. 
(a)

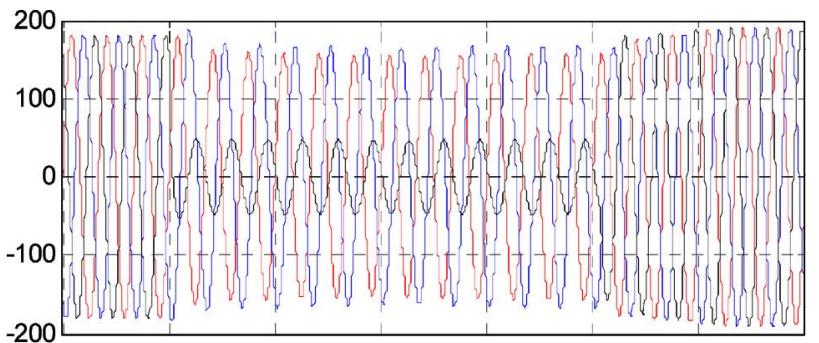

(b)

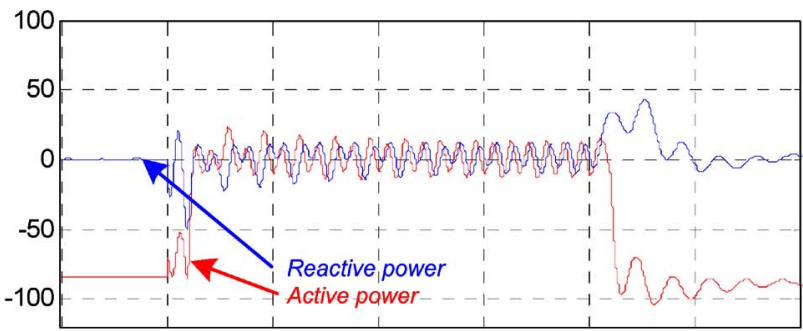

(c)

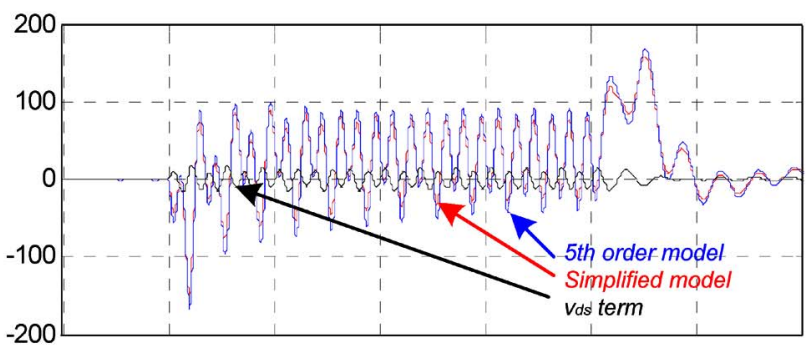

(d)

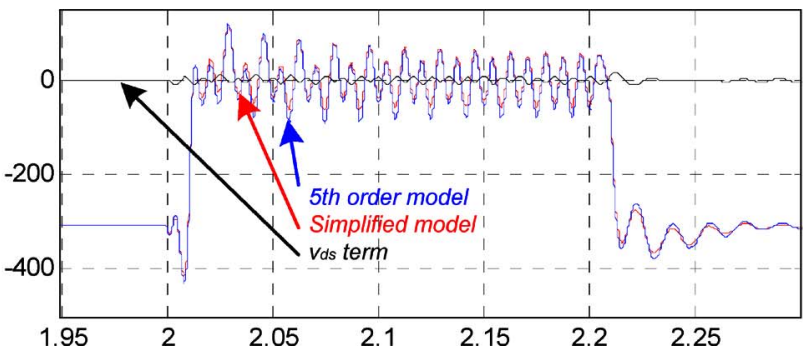

Fig. 4. Behavior of the DFIG models under one-phase-to-ground faults. (a) Grid voltage waveforms. (b) Active and reactive power (in kilovoltamperes). (c) $i_{s q}$ performance with the simplified and fifth-order models. (d) $i_{s d}$ performance with the simplified and fifth-order models.

In this test, the effect of the negative sequence voltage is translated into $120-\mathrm{Hz}$ oscillations in the $v_{d s}$ and $v_{q s}$ components, as shown in Fig. 4(c) and (d). However, the oscillating term in $v_{d s}$ is multiplied by a lower factor compared with $v_{q s}$. Hence, the influence of this first term can be neglected. This statement is endorsed by the simulation results in Fig. 4(c) and (d), where the $v_{d s}$ is plotted together with the simplified and fifth-order models.

\section{Performance Under Two-Phase-to-Ground Fault}

To evaluate the simplified model response, when severe unbalanced conditions appear in the network, a third simulation was carried out, considering a two-phase-to-ground fault.

The voltage waveforms that are obtained in this test are shown in Fig. 5(a). The behavior of the active/reactive power is depicted, in turn, in Fig. 5(b). Finally, the estimations of $i_{d s}$ and $i_{q s}$ are displayed in Fig. 5(c) and (d), respectively. (a)

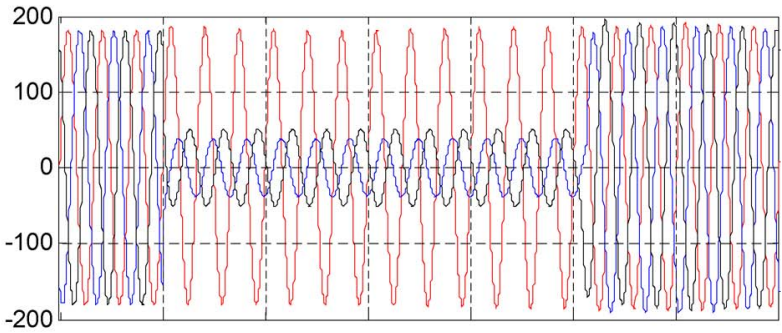

(b)

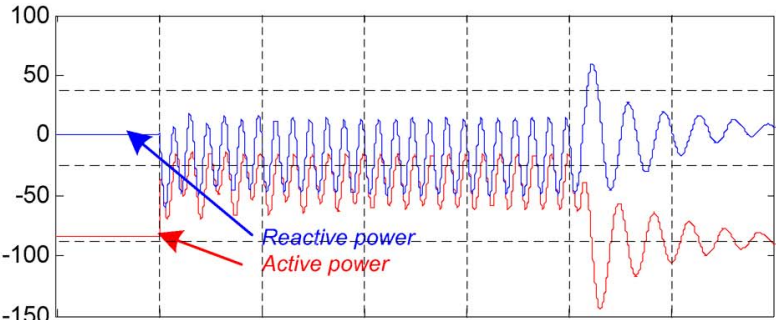

(c)

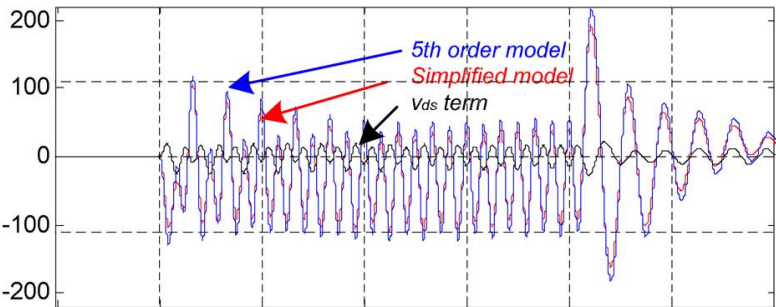

(d)

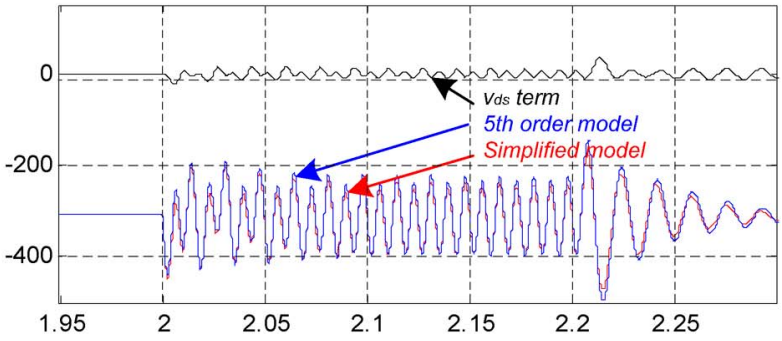

Fig. 5. Behavior of the DFIG models under two-phase-to-ground faults. (a) Grid voltage waveforms. (b) Active and reactive power (in kilovoltamperes). (c) $i_{s q}$ performance with the simplified and fifth-order models. (d) $i_{s d}$ performance with the simplified and fifth-order models.

In this case, the negative-sequence component of the voltage has a higher value compared with the previous simulation, as shown in Fig. 5(c) and (d). Due to this result, the $120-\mathrm{Hz}$ ripples in $i_{d s}$ and $i_{q s}$ are higher. However, the simplified model still accurately tracks the fifth-order model. In this point, it is worth remarking that these simulation results evidence the low influence of the $v_{d s}$ term.

The simulation results that are obtained in this section have shown that the proposed simplified model can accurately describe the dynamical behavior of a DFIG. In the following discussion, the reliability of the simplified model will be studied based on experimental results that are obtained in a scaled prototype.

\section{EXPERIMENTAL SETUP}

The accuracy of the simplified model has also been tested in an experimental setup. In this paper, the performance of the proposed model has been tested under different operating conditions such as active/reactive power set point change and voltage fault occurrence. 


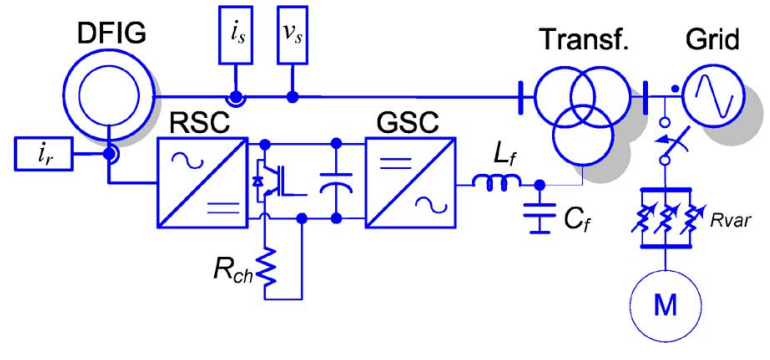

Fig. 6. DFIG experimental setup.

In this case, a comparison between different kind of models has not been carried out, but the real output currents of a DFIG have been compared with the estimated values that are obtained from the simplified model equations.

\section{A. Experimental Workbench}

A low-scale prototype of a DFIG WT, which was controlled through a back-to-back converter, has been used to carry out the experimental tests. The layout of the experimental setup is shown in Fig. 6.

As detailed in the figure, the setup consists of a DFIG, which was controlled through a back-to-back converter and connected to the grid through a $\Delta y$ transformer.

At the grid side, an induction motor is connected to the network through a controllable switch and a set of variable resistors. This part of the workbench is responsible for producing the voltage sags in the experimental network. When the induction machine is started, a high current is drained by the induction motor. This high current makes the voltage drop and hence generates sags. The depth of these sags, as well as their balanced or unbalanced features, can be controlled by adjusting the values of the variable resistors.

In the experiments in this paper, the real measurements of the rotor currents, which are injected by the converter, have been used as the input for the simplified model. The same approach was done with the stator's voltage and their frequency value, which also act as input variables.

The different labels in Fig. 6 show the variables that are measured in the prototype, which are later used as the entries for the simplified model, such as $v_{s}$ and $i_{r}$, and, on the other hand, the real value of the stator currents $i_{s}$, which will finally be compared with the estimation performed by the model.

The parameters of the experimental plant are detailed in Table II.

\section{B. Comparison of Real and Estimated Response}

Fig. 7 shows the method for estimating the stator currents. The input values correspond to the ones detailed in Fig. 6. It must be pointed out that the value of the stator's voltage frequency is calculated through a grid synchronization system, i.e., dual second-order generalized integrator-frequencylocked loop (DSOGI-FLL), which is able to estimate the frequency of the network voltage, even under unbalanced or distorted conditions.
TABLE II

SPECIFICATION OF EXPERIMENTAL SETUP

\begin{tabular}{ll}
\hline \multicolumn{1}{c}{ DFIG parameters } & Values \\
\hline Rated power & $7.5 \mathrm{kVA}$ \\
Rated stator voltage & $220 \mathrm{~V}$ \\
Rated stator frequency & $50 \mathrm{~Hz}$ \\
Stator resistance & $0.462 \Omega$ \\
Rotor resistance & $0.473 \Omega$ \\
Stator leakage inductance & $3.93 \mathrm{mH}$ \\
Rotor leakage inductance & $3.93 \mathrm{mH}$ \\
Mutual inductance & $130.4 \mathrm{mH}$ \\
Turns ratio & 1 \\
Poles pairs & 2 \\
\hline \multicolumn{1}{c}{ Power converters } & Values \\
\hline Rated power & $5 \mathrm{Kva}$ \\
Rated stator voltage & $380 \mathrm{~V}$ \\
Rated nominal current & $7 \mathrm{~A}$ \\
\hline \multicolumn{1}{c}{ DC Bus } & Values \\
\hline DC Voltage & $500 \mathrm{~V}$ \\
Capacitance & $4.7 \mathrm{mF}$ \\
\hline
\end{tabular}

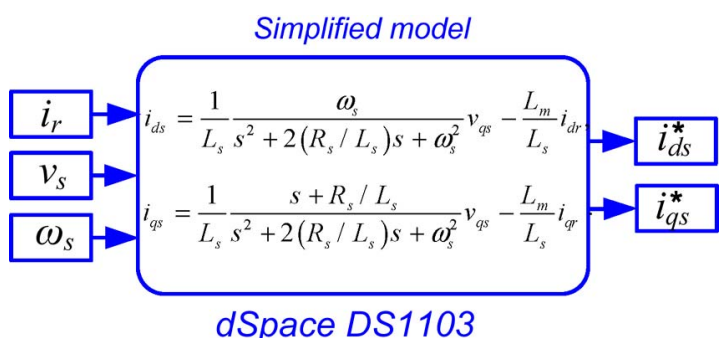

Fig. 7. Estimation of the stator currents.

In this paper, a DS1103 dSpace is used to process the experimental measurements and to program the simplified modeling equations [41].

\section{Discrete Representation of Simplified Model}

Although the simplified model has previously been presented in the continuous Laplace domain, in a real implementation, it is necessary to use a discrete model to program it in a fixed-step algorithm for the dSpace.

In this paper, (19) and (20) have been rewritten in the $z$-domain by using the Tustin approximation for continuous integrators, i.e.,

$$
\frac{1}{s}=\frac{T_{s}(z+1)}{2(z-1)}
$$

where $T_{s}$ is the sampling time of the discrete model, which is equal to $100 \mu \mathrm{s}$ in these experiments.

According to (21) and to the parameters in Table II, the resulting discrete model of (19) and (20) gives rise to

$$
\begin{aligned}
i_{d s}^{*}= & \frac{5.843 \cdot 10^{-6} z^{2}+1.169 \cdot 10^{-5} z+5.843 \cdot 10^{-6}}{z^{2}-1.998 z+0.999} \\
& \cdot v_{q s}-0.9708 \cdot i_{d r} \\
i_{q s}^{*}= & \frac{3.720 \cdot 10^{-4} z^{2}+1.805 \cdot 10^{-7} z+3.720 \cdot 10^{-4}}{z^{2}-1.998 z+0.999} \\
& \cdot v_{q s}-0.9708 \cdot i_{q r} .
\end{aligned}
$$




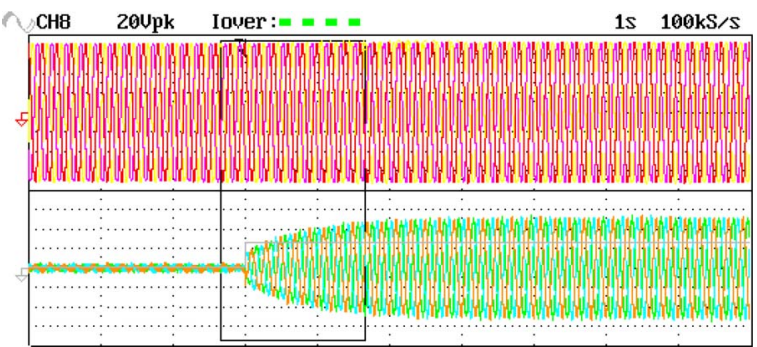

Fig. 8. Stator voltage and currents when changing the value of $P$.

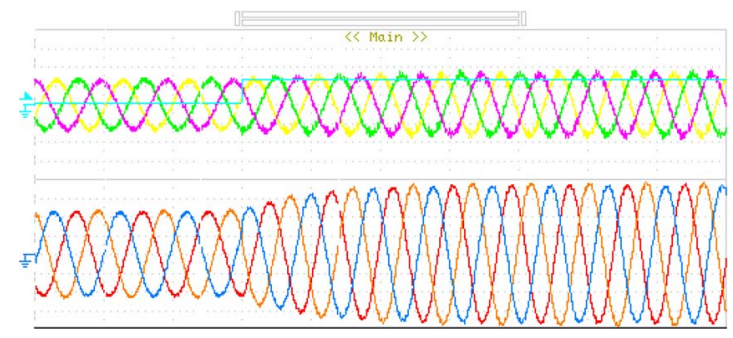

Fig. 9. Rotor voltage and currents when changing the value of $P$.

Both equations are finally implemented in the dSpace, and the resulting values of $i_{d s}^{*}$ and $i_{q s}^{*}$ are compared with the measured stator currents $i_{d s}$ and $i_{q s}$.

\section{EXPERIMENTAL RESULTS}

The dynamical performance of the simplified model was experimentally analyzed, considering different operating points of the generation plant, during steady-state and transient conditions of the network's voltage. The two first tests will consider a change in the active/reactive power set point, which consequently gives rise to a change in $i_{q s}$ and $i_{d s}$. The last experiments will be centered at testing the response of the simplified algorithm under balanced and unbalanced grid fault conditions.

\section{A. Active Power Change}

This experiment is devoted to evaluating the accuracy in the estimation of the $i_{d s}^{*}$ component with respect to its real value $i_{d s}$.

This component in the stator is directly linked to the active power delivery; therefore, the experimental plant was programmed to produce a change in the active power from $-50 \mathrm{~W}$ to $-1300 \mathrm{~W}$, whereas the $Q$ component is equal to zero, considering a totally balanced network.

The real currents that are injected by the rotor-side converter of the back-to-back converter, as well as the stator currents and voltage waveforms, are shown as follows. Fig. 8 shows the voltage and currents at the stator, whereas Fig. 9 shows the fundamental component of the voltages and injected currents at the rotor windings.

The behavior of $P$ and $Q$ is shown in Fig. 10, and for clarity, other variable have been plotted in parallel. Fig. 10(a) shows the voltage of the network. The $d q$ components are depicted in Fig. 10(b). (a)

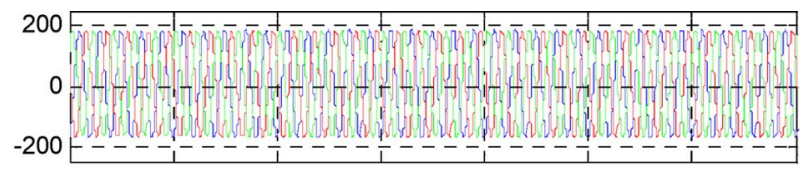

(b)

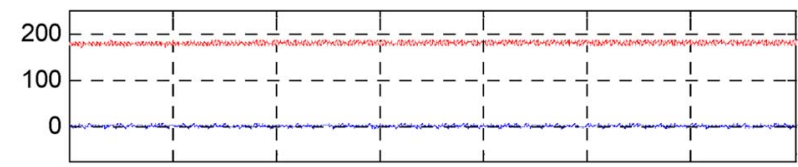

(c)

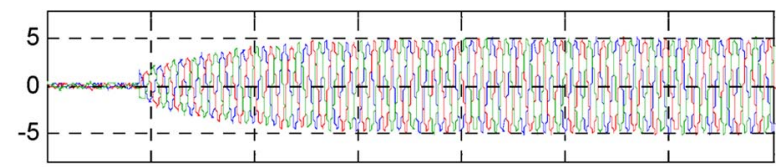

(d)

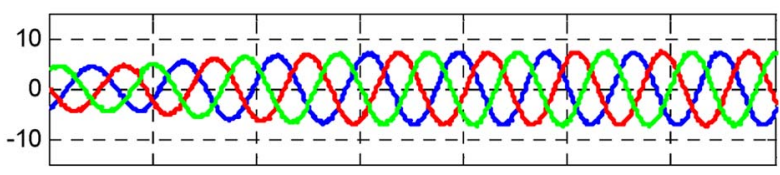

(e)

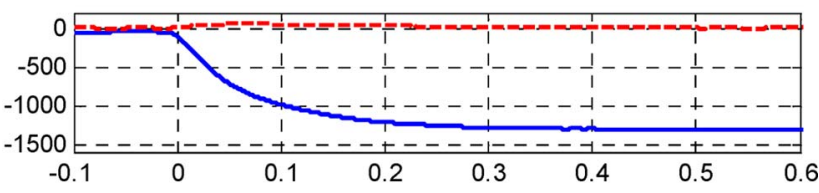

Fig. 10. Behavior of the DFIG when the active power changes from $-50 \mathrm{~W}$ to $-1.3 \mathrm{~kW}$. (a) Stator voltage in $a b c$. (b) Stator voltage in $d q 0$. (c) Stator currents in $a b c$. (d) Rotor currents in $a b c$. (e) Injected active/reactive power.

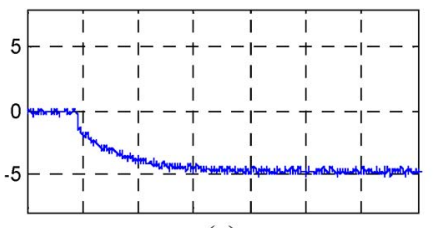

(a)

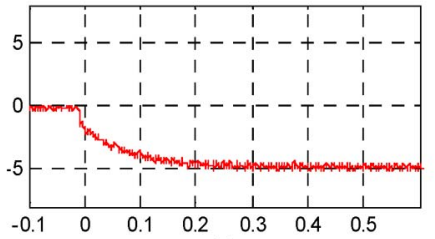

(c)

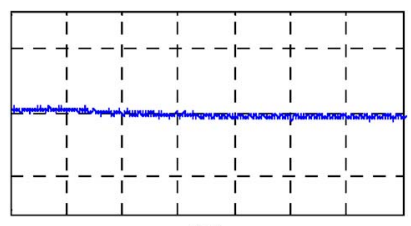

(b)

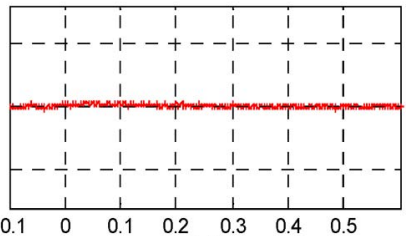

(d)
Fig. 11. Behavior of the DFIG when the active power changes from $-50 \mathrm{~W}$ to $-1300 \mathrm{~W}$. (a) Estimated $i_{d s}$ current. (b) Estimated $i_{q s}$ current. (c) Measured $i_{d s}$ current. (d) Measured $i_{q s}$ current

The stator currents are plotted in Fig. 10(c), whereas the rotor currents are shown in Fig. 10(d). Finally, the evolution of the average $P$ and $Q$ is detailed in Fig. 10(e). These figures stand out the normal operation of the system, which reaches the $P$ and $Q$ set points while injecting sinusoidal currents through the rotor that gives rise to sinusoidal stator currents.

Fig. 11 shows the results of the estimation performed by the model and the real value of the stator current in the $d q$ synchronous reference frame. In Fig. 11(a) and (c), the estimated and measured values of $i_{\mathrm{ds}}$ are plotted. On the other hand, in Fig. 11(b) and (d), the evolution of $i_{\mathrm{qs}}$ is printed. Based on these figures, the estimated response of both variables $i_{d s}^{*}$ and $i_{q s}^{*}$ perfectly match with the measured currents. This result is more remarkable for the $i_{d s}^{*}$ case, because it is the component that experiences the most noticeable transient due to the change in the active power delivery. 


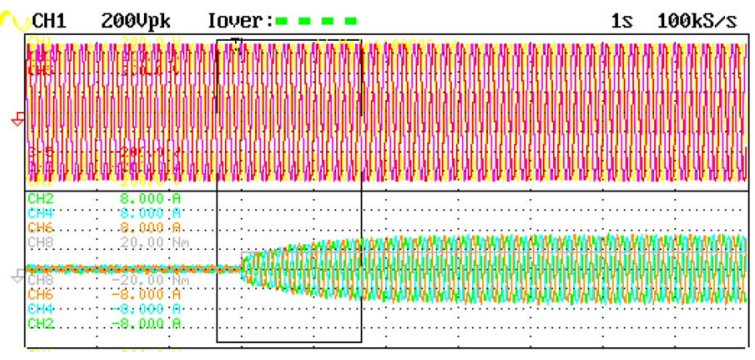

Fig. 12. Stator voltage and currents when changing the value of $Q$.

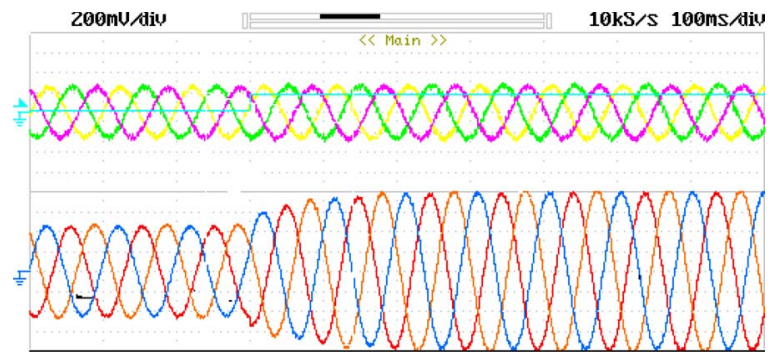

Fig. 13. Rotor voltage and currents when changing the value of $Q$.

\section{B. Reactive Power Change}

A second test was done, considering only a jump in the reactive power set point from -50 Var to -1500 Var, which will generate a change in the value of $i_{q s}$, produced by the increase in the $i_{d r}$ magnitude in the DFIG's rotor-side controller. In this case, the value of $P$ was forced almost to zero. The stator and rotor variables, which are measured at the plant in this experiment, are shown in Figs. 12 and 13, respectively.

Fig. 14 shows the performance of the injected power and the behavior of other associated variables. The voltage at the DFIG coupling point is displayed in Fig. 14(a). This magnitude is, in turn, represented in the $d q$ reference frame in Fig. 14(b). The stator currents are plotted in Fig. 14(c), whereas the rotor currents are shown in Fig. 14(d). The evolution of the average $P$ and $Q$ is presented in Fig. 14(e).

The results that are obtained in this part enable us to confirm that the plant behaves as expected by injecting the required power set point while giving rise to sinusoidal currents.

The estimation carried out by the simplified model in real time can be analyzed based on Fig. 15. In this figure, the estimated and real values of $i_{d s}$ are presented in Fig. 15(a) and (c), respectively.

The same comparison can be carried out for $i_{q s}$ in Fig. 15(b) and (d). As in the previous case, the estimation performed by the model is very satisfactory, because almost no difference can be found between the figures.

\section{Balanced Sag}

According to (19) and (20), a voltage drop in the network significantly affects the dynamics of the stator currents. The previous tests were carried out, considering balanced steadystate voltage conditions; hence, the sensitivity of the proposed model with respect to sudden voltage variations were not analyzed. In this section, the response of the simplified model will be studied when the grid experiences a balanced sag. (a)

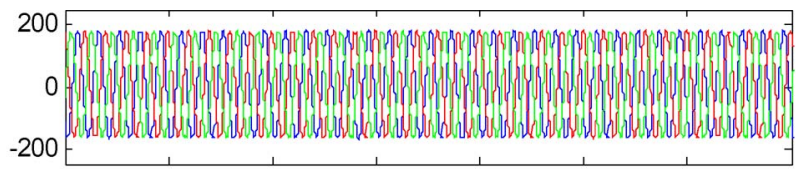

(b)

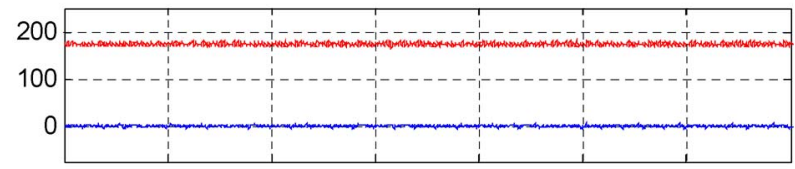

(c)

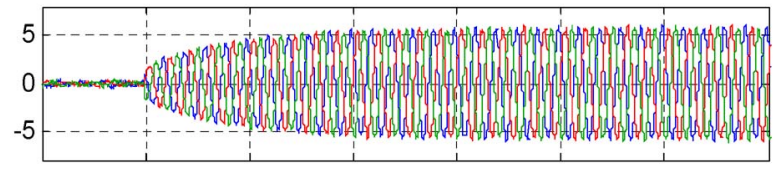

(d)

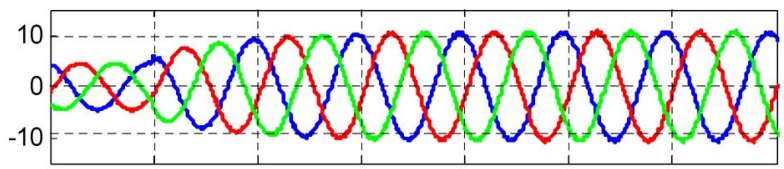

(e)

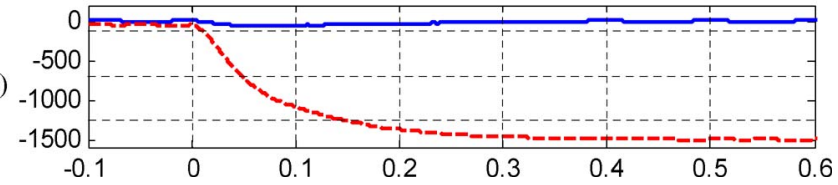

Fig. 14. Behavior of the DFIG when the reactive power changes from -50 Var to -1500 Var. (a) Stator voltage in $a b c$. (b) Stator voltage in $d q 0$. (c) Stator currents in $a b c$. (d) Rotor currents in $a b c$. (e) Injected active/reactive power.

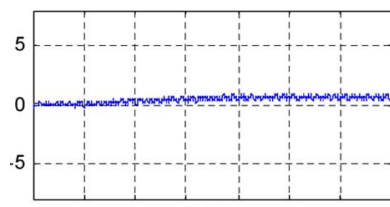

(a)

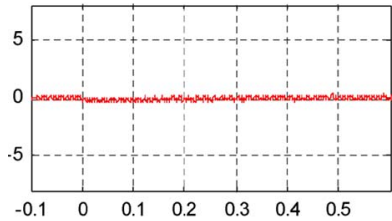

(c)

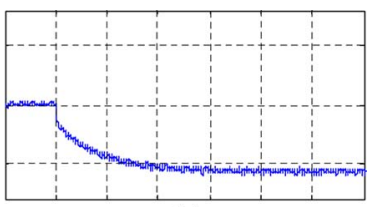

(b)

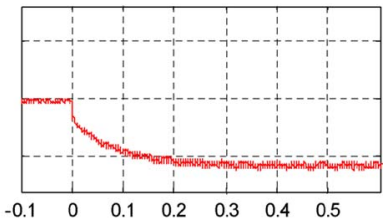

(d)
Fig. 15. Behavior of the DFIG when the reactive power changes from -50 Var to -1500 Var. (a) Estimated $i_{d s}$ current $i_{d s}^{*}$. (b) Estimated $i_{q s}$ current $i_{q s}^{*}$. (c) Measured $i_{d s}$ current. (d) Measured $i_{q s}$ current.

It should be pointed out that, in this experiment, to avoid the installation of a crowbar, a special control strategy for the rotor-side converter has been implemented. This strategy, which was presented in [42], enables us to cancel out the overcurrents in the rotor and stator windings. Nevertheless, its implementation does not interfere with the comparison between the real response of the generator and its estimated response.

In this experiment, the measured stator voltage during the sag and the injected currents are displayed in Fig. 16. As shown in the figure, the produced sag gives rise to a $63 \%$ voltage drop. In turn, the rotor voltage and currents injected by the Rotor Side Converter (RSC) are shown in Fig. 17. As for the stator currents, as shown in the figure, their magnitudes change during and after the sag. This effect is produced by the control strategy, 


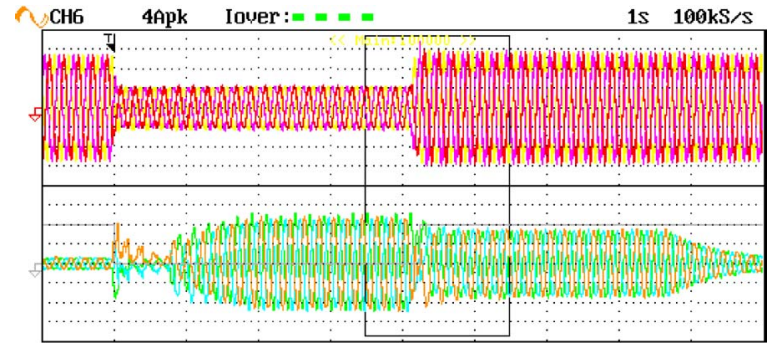

Fig. 16. Stator voltage and currents measured during the sag.

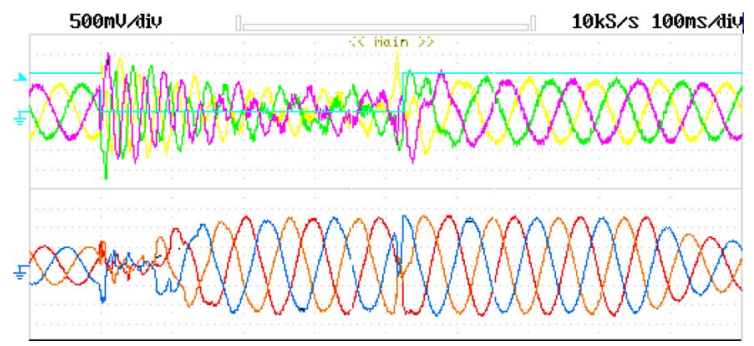

Fig. 17. Rotor voltage and currents measured during the sag.

(a)

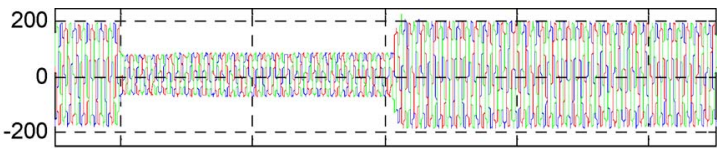

(b)

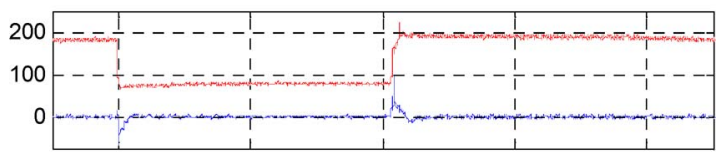

(c)

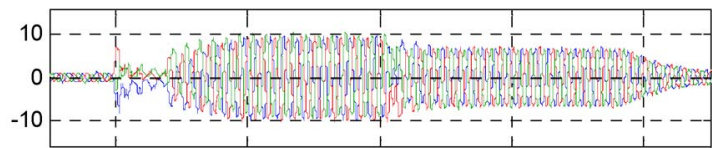

(d)

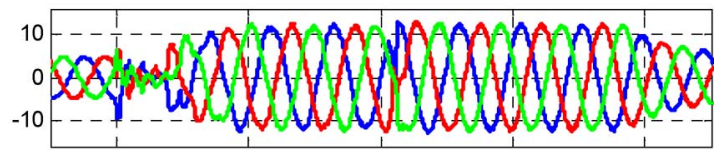

(e)

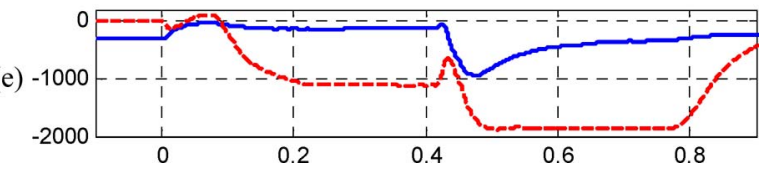

Fig. 18. Behavior of the DFIG variables under a $60 \%$ balanced voltage sag. (a) Stator voltage in $a b c$. (b) Stator voltage in $d q 0$. (c) Stator currents in $a b c$. (d) Rotor currents in $a b c$. (e) Injected active/reactive power.

which is applied to the RSC, which is oriented to support the grid by injecting as much reactive power as possible. This effect can be also observed in the rotor current dynamics in Fig. 17. As it can be noticed, the rotor currents remain under controllable limits due to the rotor-side controller.

The behavior of these variables, together with the values of $P$ and $Q$, are displayed in Fig. 18 .

In Fig. 18(b), the stator's voltages in the $d q$ components are shown. The injected currents through the stator are displayed in Fig. 18(c). In Fig. 18(d), the instantaneous currents that are provided by the RSC are displayed.

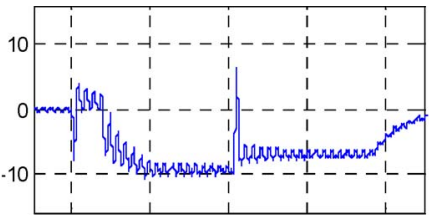

(a)

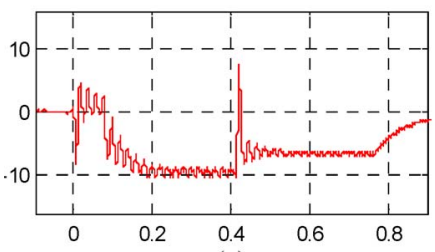

(c)

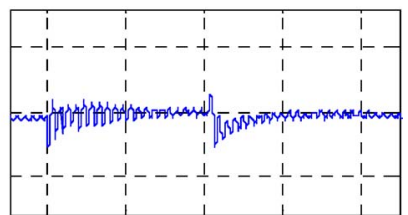

(b)

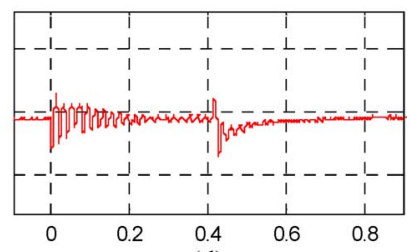

(d)
Fig. 19. Behavior of the DFIG variables under a $60 \%$ balanced voltage sag. (a) Estimated $i_{d s}$ current $i_{d s}^{*}$. (b) Estimated $i_{q s}$ current $i_{q s}^{*}$. (c) Measured $i_{d s}$ current. (d) Measured $i_{q s}$ current.

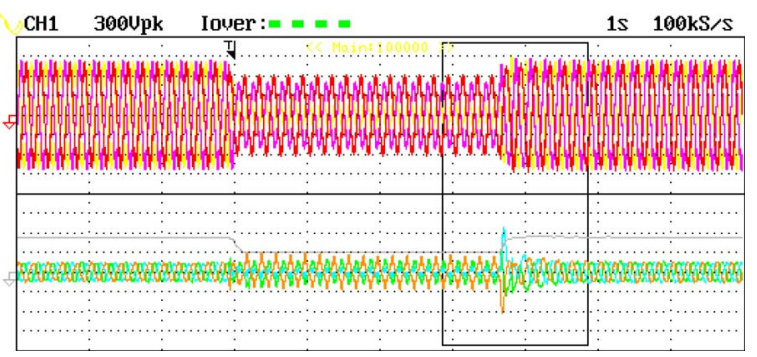

Fig. 20. Stator voltage and currents measured during the test.

Finally, in Fig. 18(e), the behavior of the power that is delivered by the stator is displayed. In this figure, it can be realized that the reference for $Q$ changes three times during this test. This operating condition enables us to carry out an intensive analysis about the accuracy of the presented model.

In this experiment, the comparison between the estimated values of the model and the real performance of the stator currents can be carried out based on Fig. 19(a). The comparison between the estimated and real values of $i_{d s}$, that can be carried out through Fig. 19(a) and (c), show an excellent response of the simplified model, despite the four transients in the reactive power that the system experiences during the test.

Likewise, the results obtained for $i_{q s}$ are also satisfactory. In this experiment, it must be pointed out that the oscillations that appear in the current components have the frequency of the grid, as stated in (19) and (23).

\section{Unbalanced Sag}

Finally, the last experiment will test the response of the model when the grid is affected by an unbalanced sag. The voltage waveforms that are measured in this test are shown in Fig. 20, together with the stator currents. Likewise, the rotor variables are depicted in Fig. 21.

In Fig. 22(a) the time response of the voltage at the stator is printed, where the unbalanced three-phase waveform can easily be noticed. This unbalance is better shown in Fig. 22(b), where the stator voltage is presented in the $d q$ reference frame. The $d q$ components are affected by a ripple with a frequency that is 


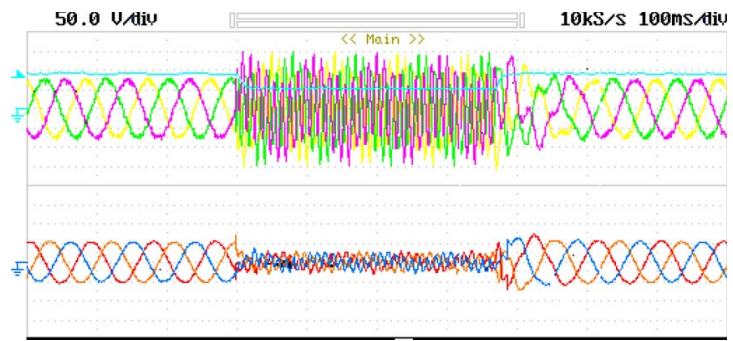

Fig. 21. Rotor voltage and currents measured during the test.

(a)

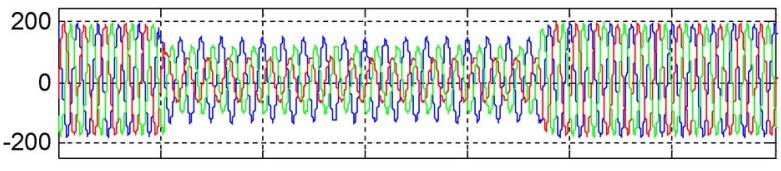

(b)

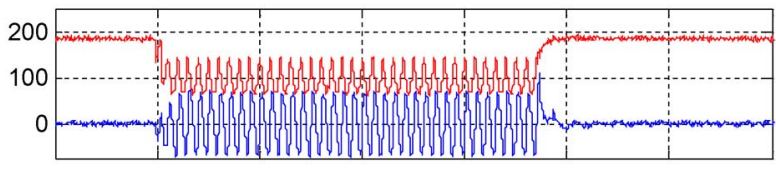

(c)

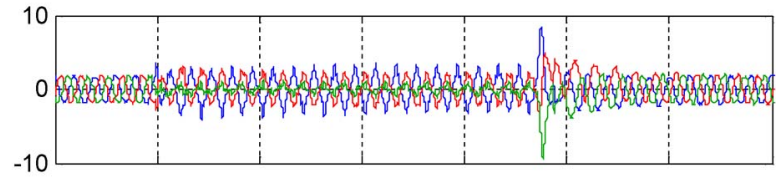

(d)

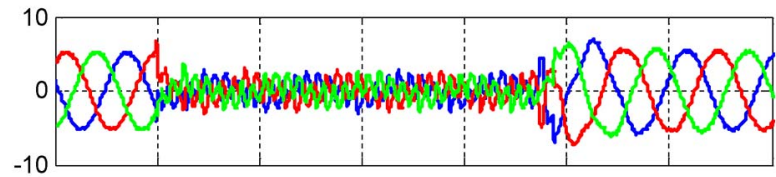

(e)

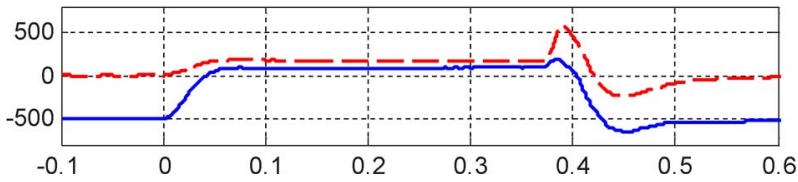

Fig. 22. Behavior of the DFIG variables under unbalanced voltage sag. (a) Stator voltage in $a b c$. (b) Stator voltage in $d q 0$. (c) Stator currents in $a b c$. (d) Rotor currents in $a b c$. (e) Injected active/reactive power.

equal to twice the network frequency due to the appearance of a negative sequence component.

In Fig. 22(c) and (d), the stator currents and the currents that are injected through the rotor are displayed. Finally, the average value of the active/reactive power is shown in Fig. 22(e).

In this paper, a current controller for the rotor-side converter has been implemented only for the positive sequence. Due to this feature, the currents that are obtained in the test are not sinusoidal, because no specific strategy that is oriented to control the unbalanced components was programmed. However, this is not a problem in terms of the analysis of the accuracy of the model, because the rotor-side converter currents are a part of the input parameters.

In Fig. 23, the estimated and real performances of the DFIG again present a good matching. In both components $i_{d s}$ and $i_{q s}$, the oscillation components include a $100-\mathrm{Hz}$ sinusoid as a result of the negative-sequence projection in a $d q$ reference frame that rotates following the positive sequence.

The results that are obtained in this test experimentally show the low influence of the $v_{d s}$ term in the simplified model compared with the $v_{q s}$ component, as stated in Section IV.

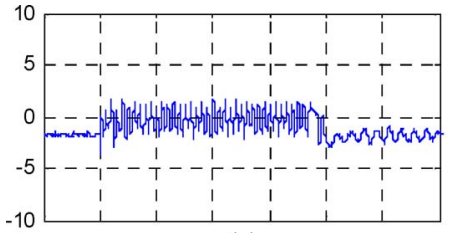

(a)

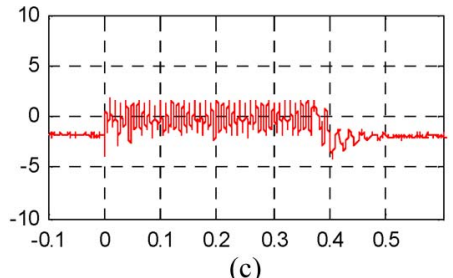

(c)

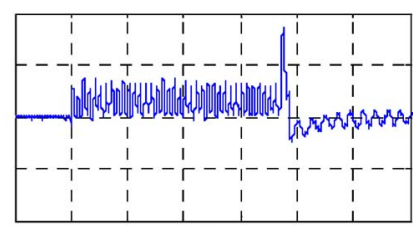

(b)

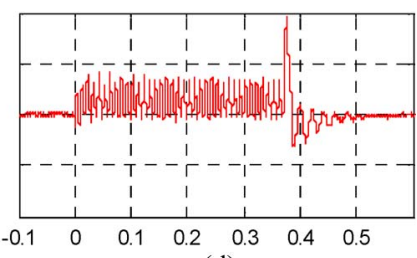

(d)
Fig. 23. Behavior of the DFIG variables under unbalanced voltage sag conditions. (a) Estimated $i_{d s}$ current $i_{d s}^{*}$. (b) Estimated $i_{q s}$ current $i_{q s}^{*}$. (c) Measured $i_{d s}$ current. (d) Measured $i_{q s}$ current.

\section{CONCLUSION}

The simplified model that has been presented in this paper has shown to be an effective tool for performing straightforward analysis of the DFIG's performance when transients in the rotor current or in the stator voltage occur. These transient conditions correspond mainly to the following features: 1) changes in the active/reactive power that will be injected through the stator; 2) balanced voltage drops due to grid faults; and 3) unbalanced voltage drops due to grid faults.

The reliability of this model has been tested through simulations by using PSCAD/EMTDC and also through experiments that are performed in a scaled prototype, giving rise to good results in both cases.

The reliability of this simplified model has permitted to carry out simulations of large-scale wind power applications, because it is possible to emulate the behavior of a DFIG through two simple second-order transfer functions. As a consequence, simulating the behavior of several DFIG-WTs does not take as much computational time as when using a fifth-order model.

In addition, the simplified model would permit us to design simple strategies that are oriented to enhance the performance of DFIGs under sag conditions. Although the same conclusions can be reached using a more complex model, this simplified version enables us to conduct a more intuitive estimation about the behavior of the system.

\section{REFERENCES}

[1] Integrating Wind Developing Europe's Power Market for the Large-Scale Integration of Wind Power, Mar. 2009. [Online]. Available: www.ewea.org

[2] Wind Power Observatory, Mar. 2009. [Online]. Available: www. aeeolica.es

[3] The Spanish Electrical System Report for 2008, REE, Madrid, Spain. [Online]. Available: www.ree.es

[4] A. Zervos and C. Kjaer, Pure Power: Wind Energy Scenarios for 2030, EWEA, Apr. 2008. [Online]. Available: http://www.ewea.org/index. php?id=11

[5] F. Iov, A. Hansen, P. Sorensen, and N. Cutululis, Mapping of grid faults and grid codes-Risoe-R-1617(EN), Risoe, 2007.

[6] E-ON Netz GmbH, Grid-Code-High and Extra High Voltage, Apr. 2006. [Online]. Available: http://www.eon-netz.com

[7] National Grid Electricity Transmission, The Grid Code: Revision 31 in United Kingdom no. 3, Oct. 2008. [Online]. Available: http://www. nationalgrid.com/uk 
[8] "PO-12.3 Requisitos de respuesta frente a huecos de tension de las instalaciones eolicas," Comisión Nacional de Energía, Oct. 2006.

[9] Transmission Lines Department (Denmark), Wind Turbines Connected to Grids With Voltages Below 100 kV-Technical Regulations TF 3.2.6, May 2004. [Online]. Available: http://www.energinet.dk

[10] M. Tsili and S. Papathanassiou, "A review of grid code technical requirements for wind farms," IET Renew. Power Gener, vol. 3, no. 3, pp. 308-332, Sep. 2009.

[11] F. C. Blaabjerg, Power Electronics for Modern Wind Turbines. San Rafael, CA: Morgan \& Claypool Publishers, 2006, ser. Synthesus Lectures on Power Electronics.

[12] R. W. De Doncker and D. W. Novotny, "The universal field-oriented controller," IEEE Trans. Ind. Appl., vol. 30, no. 1, pp. 92-100, Jan./Feb. 1994.

[13] R. Pena, J. C. Clare, and G. M. Asher, "Doubly fed induction generator using back-to-back PWM converters and its application to variable-speed wind-energy generation," Proc. Inst. Elect. Eng.-Elect. Power Appl., vol. 143, no. 3, pp. 231-241, May 1996.

[14] R. Pena, J. Clare, and G. Asher, "A doubly fed induction generator using back-to-back PWM converters supplying an isolated load from a variablespeed wind turbine," Proc. Inst. Elect. Eng._Elect. Power Appl., vol. 143, no. 5, pp. 380-387, Sep. 1996.

[15] L. Xu and Y. Wang, "Dynamic modeling and control of DFIG-based wind turbines under unbalanced network conditions," IEEE Trans. Power Syst., vol. 20, no. 1, pp. 314-323, Feb. 2007.

[16] L. Xu, "Enhanced control and operation of DFIG-based wind farms during network unbalance," IEEE Trans. Energy Convers., vol. 23, no. 4, pp. 1073-1081, Dec. 2008.

[17] L. Xu, "Coordinated control of DFIG's rotor and grid-side converters during network unbalance," IEEE Trans. Power Electron., vol. 23, no. 3, pp. 1041-1049, May 2008.

[18] K. Lima, A. Luna, P. Rodriguez, E. Watanabe, R. Teodorescu, and F. Blaabjerg, "Doubly fed induction generator control under voltage sags," in Proc. IEEE ENERGY, Nov. 17-18, 2008, pp. 1-6.

[19] J. M. Carrasco, L. G. Franquelo, J. T. Bialasiewicz, E. Galvan, R. C. PortilloGuisado, M. A. M. Prats, J. I. Leon, and N. Moreno-Alfonso, "Power-electronic systems for the grid integration of renewable energy sources: A survey," IEEE Trans. Ind. Electron., vol. 53, no. 4, pp. 10021016, Aug. 2006.

[20] P. Rodriguez, A. V. Timbus, R. Teodorescu, M. Liserre, and F. Blaabjerg, "Flexible active power control of distributed power generation systems during grid faults," IEEE Trans. Ind. Electron., vol. 54, no. 5, pp. 25832592, Oct. 2007

[21] S. Alepuz, S. Busquets-Monge, J. Bordonau, J. A. Martinez-Velasco, C.A. Silva, J. Pontt, and J. Rodriguez, "Control strategies based on symmetrical components for grid-connected converters under voltage dips," IEEE Trans. Ind. Electron., vol. 56, no. 6, pp. 2162-2174, Jun. 2009.

[22] J. Hu, Y. He, L. Xu, and B. W. Williams, "Improved control of DFIG systems during network unbalance using PI-R current regulators," IEEE Trans. Ind. Electron., vol. 56, no. 2, pp. 439-451, Feb. 2009.

[23] S. Karimi, A. Gaillard, P. Poure, and S. Saadate, "FPGA-based real-time power converter failure diagnosis for wind energy conversion systems," IEEE Trans. Ind. Electron., vol. 55, no. 12, pp. 4299-4308, Dec. 2008.

[24] M. Malinowski, S. Stynski, W. Kolomyjski, and M. P. Kazmierkowski, "Control of three-level PWM converter applied to variable-speed-type turbines," IEEE Trans. Ind. Electron., vol. 56, no. 1, pp. 69-77, Jan. 2009.

[25] X. Tu, L.-A. Dessaint, N. Fallati, and B. De Kelper, "Modeling and real-time simulation of internal faults in synchronous generators with parallel-connected windings," IEEE Trans. Ind. Electron., vol. 54, no. 3, pp. 1400-1409, Jun. 2007.

[26] R. Pea, R. Cerdenas, J. Proboste, G. Asher, and J. Clare, "Sensorless control of doubly fed induction generators using a rotor-current-based MRAS observer," IEEE Trans. Ind. Electron., vol. 55, no. 1, pp. 330-339, Jan. 2008.

[27] P. Krause, O. Wasynczuk, and S. Sudhoff, Analysis of Electric Machinery and Drive Systems, 2nd ed. New York: Wiley-IEEE Press, 2002.

[28] P. Kundur, Power System Stability and Control. New York: McGraw-Hill, 1994

[29] W. Leonhard, Control of Electrical Drives, 3rd ed. New York: SpringerVerlag, 2001

[30] Y. Zhou, P. Bauer, J. Ferreira, and J. Pierik, "Operation of grid-connected DFIG under unbalanced grid voltage condition," IEEE Trans. Energy Convers., vol. 24, no. 1, pp. 240-246, Mar. 2009.

[31] V. Akhmatov and H. Knudsen, "Large penetration of wind and dispersed generation into Danish power grid," Elect. Power Syst. Res., vol. 77, no. 9, pp. 1228-1238, Jul. 2007.
[32] J. B. Ekanayake, L. Holdsworth, and N. Jenkins, "Comparison of fifthorder and third-order machine models for doubly fed induction generator (DFIG) wind turbines," Elect. Power Syst. Res., vol. 67, no. 3, pp. 207215, Dec. 2003.

[33] A. Feijoo, J. Cidras, and C. Carrillo, "A third-order model for the doubly fed induction machine," Elect. Power Syst. Res., vol. 56, no. 2, pp. 121127, Nov. 2000.

[34] O. Wasynezuk, D. Yi-Min, and P. C. Krause, "Theory and comparison of reduced order models of induction machines," IEEE Trans. Power App. Syst., vol. PAS-104, no. 3, pp. 598-606, Mar. 1985.

[35] P. Ledesma and J. Usaola, "Effect of neglecting stator transients in doubly fed induction generators models," IEEE Trans. Energy Convers., vol. 19, no. 2, pp. 459-461, Jun. 2004.

[36] A. Petersson, T. Thiringer, L. Harnefors, and T. Petru, "Modeling and experimental verification of grid interaction of a DFIG wind turbine," IEEE Trans. Energy Convers., vol. 20, no. 4, pp. 878-886, Dec. 2005.

[37] E. Levi, "Multiphase electric machines for variable-speed applications," IEEE Trans. Ind. Electron., vol. 55, no. 5, pp. 1893-1909, May 2008.

[38] Q. Zeng and L. Chang, "An advanced SVPWM-based predictive current controller for three-phase inverters in distributed generation systems," IEEE Trans. Ind. Electron., vol. 55, no. 3, pp. 1235-1246, Mar. 2008.

[39] M. Bollen, P. Goossens, and A. Robert, "Assessment of voltage dips in HV-networks: Deduction of complex voltages from the measured RMS voltages," IEEE Trans. Power Del., vol. 19, no. 2, pp. 783-790, Apr. 2004.

[40] F. Blaabjerg, R. Teodorescu, M. Liserre, and A. V. Timbus, "Overview of control and grid synchronization for distributed power generation systems," IEEE Trans. Ind. Electron., vol. 53, no. 5, pp. 1398-1409, Oct. 2006.

[41] R. Teodorescu, M. Bech, F. Blaabjerg, and J. Pedersen, "A new approach in teaching power electronics control of electrical drives using real-time systems," in Proc. 7th Workshop COMPEL, Jul. 16-18, 2000, pp. 221-226.

[42] F. K. A. Lima, A. Luna, P. Rodriguez, E. H. Watanable, and F. Blaabjerg, "Rotor voltage dynamics in the doubly fed induction generator during grid faults," IEEE Trans. Power Electron., vol. 25, no. 1, pp. 118-130, Jan. 2010.

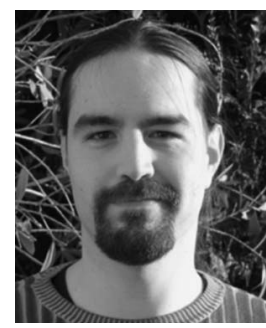

Alvaro Luna (S'07) received the B.Sc., M.Sc., and $\mathrm{Ph} . \mathrm{D}$. degrees in electrical engineering from the Technical University of Catalonia (UPC), Barcelona, Spain, in 2001, 2005, and 2009, respectively.

In 2005 , he joined the faculty of UPC, where he is currently an Assistant Professor with the Department of Electrical Engineering. His research interests include wind turbines control, integration of distributed generation, and power conditioning.

Dr. Luna is a Student Member of the IEEE Power Electronics Society, the IEEE Industrial Electronics Society, and the IEEE Industrial Applications Society.

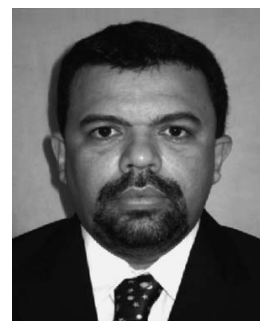

Francisco Kleber de Araujo Lima received the B.Sc. and M.Sc. degrees from the Federal University of Ceará, Fortaleza, Brazil, in 1998 and 2003, respectively, and the Ph.D. degree from the Federal University of Rio de Janeiro, Rio de Janeiro, Brazil, in 2009 .

He is currently an Adjunct Professor with the Energy Processing and Control Group, Department of Electrical Engineering, Federal University of Ceará. His research interests include wind power generation, flexible ac transmission systems (FACTS), power-factor-correction techniques, and renewable energy systems.

Dr. de Araujo Lima is a member of the Brazilian Society of Power Electronics. 


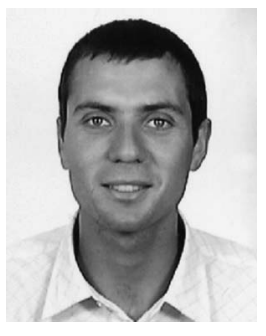

David Santos received the M.Sc. degree in electrical and electronic engineering from Escuela Técnica Superior de Ingenieros Industriales, Universidad Politécnica de Madrid, Madrid, Spain, in 1997, and the M.S. degree in control engineering from the École Supérieure d'Électricité (SUPÉLEC), Paris, France. He is currently working toward the Ph.D. degree at the University Carlos III of Madrid, Madrid.

He is currently an Assistant Lecturer with the Department of Electrical Engineering, University Carlos III of Madrid. Prior to this post, he was with Ecotecnia (now Alsthom Ecotecnia) from 2000 to 2001 and with Iberdrola from 2001 to 2007. His research interests include power electronics, application of power electronics to power systems, and advanced control techniques applied to renewable energy.

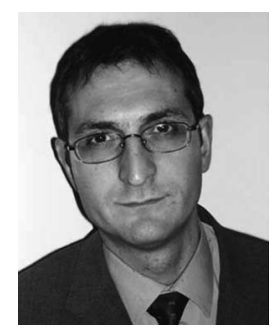

Pedro Rodríguez (S'99-M'04-SM'10) received the B.S. degree in electrical engineering from the University of Granada, Granada, Spain, in 1989, and the M.S. and Ph.D. degrees in electrical engineering from the Technical University of Catalonia (UPC), Barcelona, Spain, in 1994 and 2004, respectively.

In 1990, he joined the faculty of UPC as an Assistant Professor, and he became an Associate Professor in 1993. He was a Researcher with the Center for Power Electronics Systems, Virginia Polytechnic Institute and State University, Blacksburg, in 2005, and with the Institute of Energy Technology, Aalborg University, Aalborg, Denmark, in 2006. He is currently the Head of the Research Group on Renewable Electrical Energy Systems, Department of Electrical Engineering, UPC. He is a coauthor of about 100 papers in technical journals and conference proceedings. He is the holder of five patents. His research interests include integration of distributed energy systems, power conditioning, and control of power converters.

Dr. Rodríguez is a member of the IEEE Power Electronics, IEEE Industrial Electronics (IES), IEEE Industry Application Societies, and IEEE IES Technical Committee on Renewable Energy Systems. He has coorganized special sessions in several IEEE conferences on power electronics applied to renewable energies. He is an Associate Editor of the IEEE TRANSACTIONS ON POWER ELECTRONICS and the Committee Chair of the IEEE IES Gold and Student Activities.

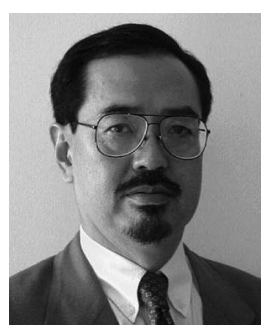

Edson H. Watanabe (S'79-M'81-SM'02) was born in Rio de Janeiro, Brazil, on November 7, 1952. He received the B.Eng. degree in electronics engineering and the M.Eng. degree from the Federal University of Rio de Janeiro, Rio de Janeiro, in 1975 and 1976, respectively, and the D.Eng. degree from the Tokyo Institute of Technology, Tokyo, Japan, in 1981.

In 1981, he was an Associate Professor with the Alberto Luiz Coimbra Institute and Graduate School of Research and Engineering (COPPE), Federal University of Rio de Janeiro, where he became a Professor in 1993 and currently teaches power electronics. His research interests include converters analysis, modeling, and design, active filters, and flexible ac transmission systems (FACTS) technologies.

Dr. Watanabe is a member of the Institute of Electrical Engineers, Japan, Brazilian Society for Automatic Control, Brazilian Power Electronics Society, International Council on Large Electric Systems (CIGRE), IEEE Power Engineering Society, IEEE Industry Applications Society, and IEEE Power Electronics Society. In 2005, he was admitted to the National Order of Scientific Merit, Brazil.

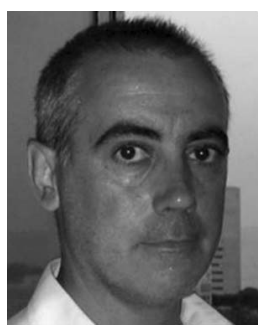

Santiago Arnaltes (M'02) received the Ph.D. degree in electrical engineering from the Polytechnic University of Madrid, Madrid, Spain, in 1993.

Since 1997, he has been an Associate Professor with the Department of Electrical Engineering, University Carlos III of Madrid, Madrid. His research interests include grid integration of wind energy and control of electrical drives and flexible ac transmission systems (FACTS), mainly for wind energy applications. 